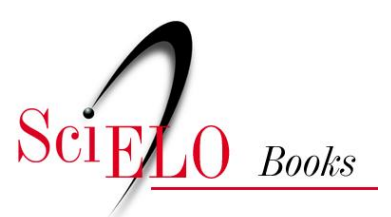

\title{
Ordem Pleuronectiformes
}

\author{
Ana Cristina Teixeira Bonecker \\ Claudia Akemi Pereira Namiki \\ Márcia Salustiano de Castro \\ Paula Nepomuceno Campos
}

\section{SciELO Books / SciELO Livros / SciELO Libros}

BONECKER, ACT., et al. Ordem Pleuronectiformes. In Catalogo dos estágios iniciais de desenvolvimento dos peixes da bacia de Campos [online]. Curitiba: Sociedade Brasileira de Zoologia, 2014, pp. 266-275. Zoologia: guias e manuais de identificação series. ISBN 978-85-98203-10-2.

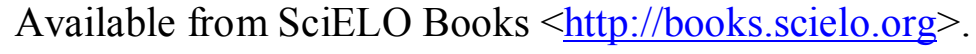

\section{(1)(9)(2)}

All the contents of this chapter, except where otherwise noted, is licensed under a Creative Commons Attribution-Non Commercial-ShareAlike 3.0 Unported.

Todo o conteúdo deste capítulo, exceto quando houver ressalva, é publicado sob a licença Creative Commons Atribuição Uso Não Comercial - Partilha nos Mesmos Termos 3.0 Não adaptada.

Todo el contenido de este capítulo, excepto donde se indique lo contrario, está bajo licencia de la licencia Creative Commons Reconocimento-NoComercial-CompartirIgual 3.0 Unported. 


\section{ORDEM PLEURONECTIFORMES}

A ordem Pleuronectiformes é composta por 14 famílias com aproximadamente 678 espécies. A maioria é marinha, mas existem cerca de dez espécies que ocorrem apenas em ambientes de água doce. Algumas espécies originalmente de água doce podem entrar eventualmente em regiões estuarinas e marinhas, enquanto outras espécies marinhas ocasionalmente ocorrem na água doce.

As larvas são bilateralmente simétricas e entre 10 e $25 \mathrm{~mm}$ sofrem a metamorfose, quando um dos olhos migra para um dos lados do corpo. A partir dessa fase, ocorre uma assimetria, e há um aumento do pigmento no lado onde o olho está localizado. Nesse estudo a ordem Pleuronectiformes é representada pelas famílias Paralichthyidae, Bothidae e Cynoglossidae. 


\section{Família Paralichthyidae}

A família Paralichthyidae é marinha, raramente registrada em água doce, e ocorre nos oceanos Atlântico, Índico e Pacífico. Compreende 16 gêneros com 105 espécies. Os olhos após a metamorfose estão posicionados do lado esquerdo da cabeça na maioria das espécies. As nadadeiras dorsal e anal não são confluentes com a nadadeira caudal. As nadadeiras pélvica e peitoral estão presentes.

No Brasil já foram identificadas 19 espécies nas fases de larva e adulto. Nesse estudo são contempladas as espécies Citharichthys sp. e Syacium papillosum. 


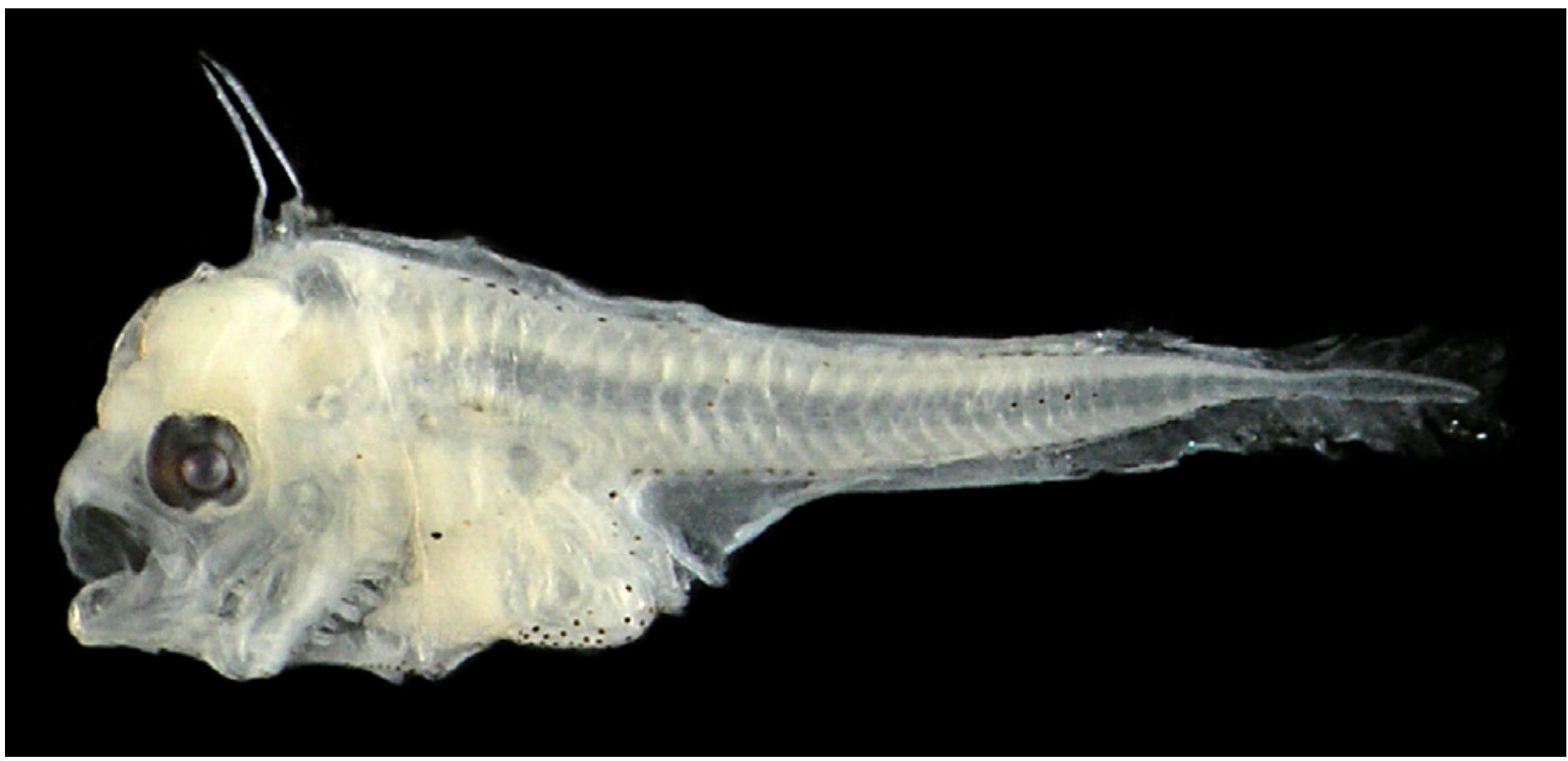

Figura 152: Citharichthys sp. DZUFRJ 20989; Pré-flexão; CP 3,5 mm.

\section{Citharichthys sp.}

As larvas de Citharichthys são caracterizadas desde o estágio de pré-flexão por apresentarem pigmentos na região da cauda, na altura da linha lateral, podendo em algumas espécies formar uma barra. Blocos de pigmentos estão presentes nas margens dorsal e ventral do corpo. Dependendo da espécie pode ter dois ou três primeiros raios da nadadeira dorsal alongados e um raio longo na nadadeira pélvica. Algumas espécies possuem espinhos no pré-opérculo. O número de miômeros varia aproximadamente entre 33 e 37. No Brasil já foram registradas as espécies Citharichthys arenaceus Evermann \& Marsh, 1900; Citharichthys cornutus (Günther, 1880); Citharichthys dinoceros Goode \& Bean, 1886; Citharichthys macrops Dresel, 1885 e Citharichthys spilopterus Günther, 1862.

Tamanho: pré-flexão 3,2 mm.

Habitat: a maioria das espécies de Citharichthys registradas na literatura é marinha e demersal, com algumas ocorrendo em águas salobra e doce. A profundidade de ocorrência varia muito entre as espécies chegando a $1.800 \mathrm{~m}$.

\section{Georreferenciamento}

\begin{tabular}{|c|c|c|c|c|c|c|c|c|}
\hline DZUFRJ & Latitude (S) & Longitude (W) & Data & $\begin{array}{c}\text { Tipo de } \\
\text { arrasto }\end{array}$ & $\begin{array}{c}\text { Profundidade } \\
\text { de coleta }\end{array}$ & Rede & $\begin{array}{c}\text { Malha } \\
\text { ( } \boldsymbol{\mu m}_{\mathbf{m}}\end{array}$ & $\begin{array}{c}\text { No. de } \\
\text { inds. }\end{array}$ \\
\hline 675 & $22^{\circ} 33^{\prime} 477^{\prime \prime}$ & $040^{\circ} 12^{\prime} 20,5^{\prime \prime}$ & $17 / 05 / 2002$ & oblíquo & $50 \mathrm{~m}$ & bongô & 500 & 1 \\
\hline
\end{tabular}

Referências: Fahay, 1983; Lyczkowski-Shultz \& Bond, 2006; Macedo \& Monteiro-Ribas, 2006. 


\section{Syacium}

papillosum

\section{(Linnaeus, 1758)}

A principal característica das larvas dessa espécie é a presença de dois espinhos na região do crânio (um de cada lado), mesmo em larvas muito pequenas, no estágio de pré-flexão. Possui entre quatro e sete espinhos pré-operculares. A partir de 3,0 mm de comprimento tem entre cinco e oito raios anteriores da nadadeira dorsal alongados. Possui cinco grupos de pigmentos na região dorsal do corpo, três a quatro na região ventral, dois na linha lateral na região da cauda. O número de miômeros varia entre 33 e 36.

Tamanho: pré-flexão 3,2-5,0 mm; flexão $6,5 \mathrm{~mm}$.

Habitat: espécie marinha, demersal, associada a formações coralinas, ocorre entre 9 e 140 m de profundidade, normalmente em profundidades inferiores a $90 \mathrm{~m}$.

Nome vulgar: Linguado do olho riscado.

\section{Georreferenciamento}

\begin{tabular}{|c|c|c|c|c|c|c|c|c|}
\hline DZUFR & Latitude (S) & Longitude (W) & Data & $\begin{array}{c}\text { Tipo de } \\
\text { arrasto }\end{array}$ & $\begin{array}{c}\text { Profundidade } \\
\text { de coleta }\end{array}$ & Rede & $\begin{array}{c}\text { Malha } \\
\text { ( } \boldsymbol{\mu m} \text { ) }\end{array}$ & $\begin{array}{c}\text { No. de } \\
\text { inds. }\end{array}$ \\
\hline 487 & $22^{\circ} 33^{\prime} 37,0^{\prime \prime}$ & $040^{\circ} 19^{\prime} 10,0^{\prime \prime}$ & $17 / 05 / 2002$ & oblíquo & $50 \mathrm{~m}$ & bongô & 500 & 5 \\
\hline 506 & $22^{\circ} 31^{\prime} 27,0^{\prime \prime}$ & $040^{\circ} 16^{\prime} 56,0^{\prime \prime}$ & $17 / 05 / 2002$ & oblíquo & $600 \mathrm{~m}$ & cilíndrico-cônica & 500 & 3 \\
\hline 527 & $22^{\circ} 34^{\prime} 05,0^{\prime \prime}$ & $040^{\circ} 19^{\prime} 40,0^{\prime \prime}$ & $17 / 05 / 2002$ & oblíquo & $600 \mathrm{~m}$ & cilíndrico-cônica & 500 & 14 \\
\hline 542 & $22^{\circ} 32^{\prime} 03,0^{\prime \prime}$ & $040^{\circ} 17^{\prime} 21,0^{\prime \prime}$ & $19 / 05 / 2002$ & oblíquo & $30 \mathrm{~m}$ & bongô & 330 & 4 \\
\hline 571 & $22^{\circ} 32^{\prime} 03,0^{\prime \prime}$ & $040^{\circ} 17^{\prime} 21,0^{\prime \prime}$ & $19 / 05 / 2002$ & oblíquo & $30 \mathrm{~m}$ & bongô & 500 & 1 \\
\hline 581 & $22^{\circ} 33^{\prime} 37,0^{\prime \prime}$ & $040^{\circ} 19^{\prime} 10^{\prime \prime} 0^{\prime \prime}$ & $17 / 05 / 2002$ & oblíquo & $50 \mathrm{~m}$ & bongô & 330 & 3 \\
\hline 618 & $22^{\circ} 36^{\prime} 54,9^{\prime \prime}$ & $040^{\circ} 09^{\prime} 19,4^{\prime \prime}$ & $16 / 05 / 2002$ & oblíquo & $50 \mathrm{~m}$ & bongô & 500 & 2 \\
\hline 694 & $22^{\circ} 33^{\prime} 477^{\prime \prime}$ & $040^{\circ} 12^{\prime} 20,5^{\prime \prime}$ & $17 / 05 / 2002$ & oblíquo & $50 \mathrm{~m}$ & bongô & 500 & 3 \\
\hline
\end{tabular}

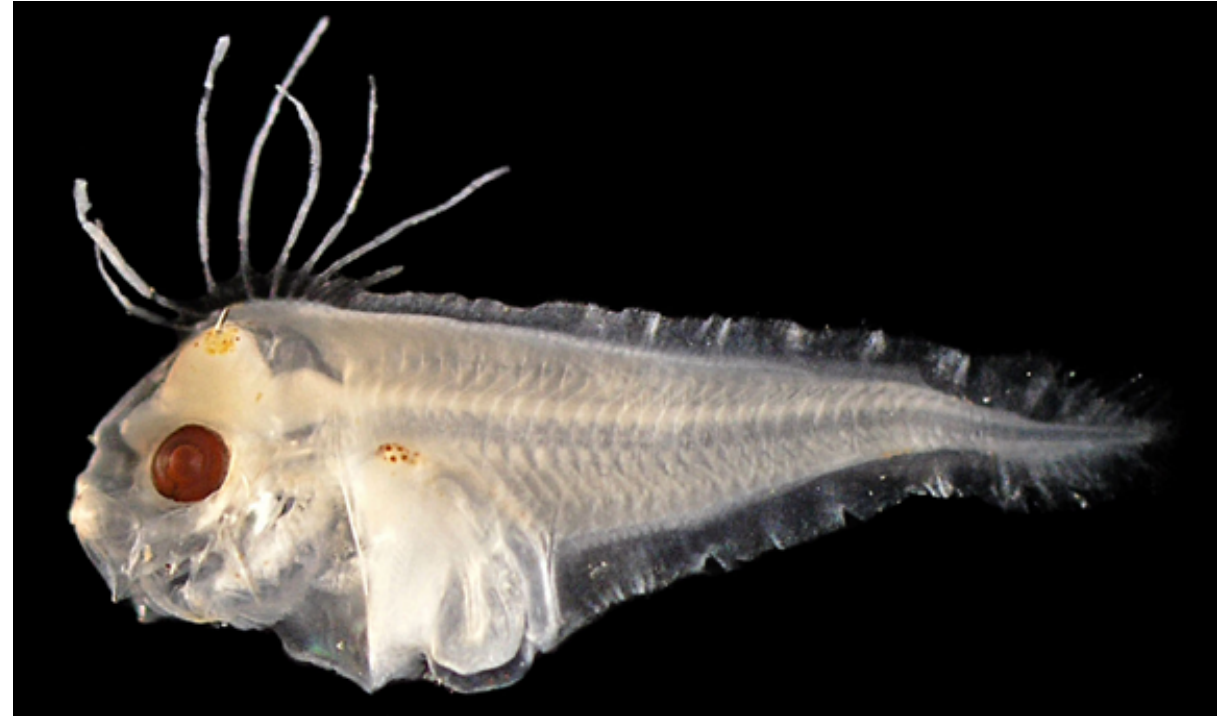

Figura 153 - A: Syacium papillosum. DZUFRJ 13431; Pré-flexão; CP 5,0 mm.

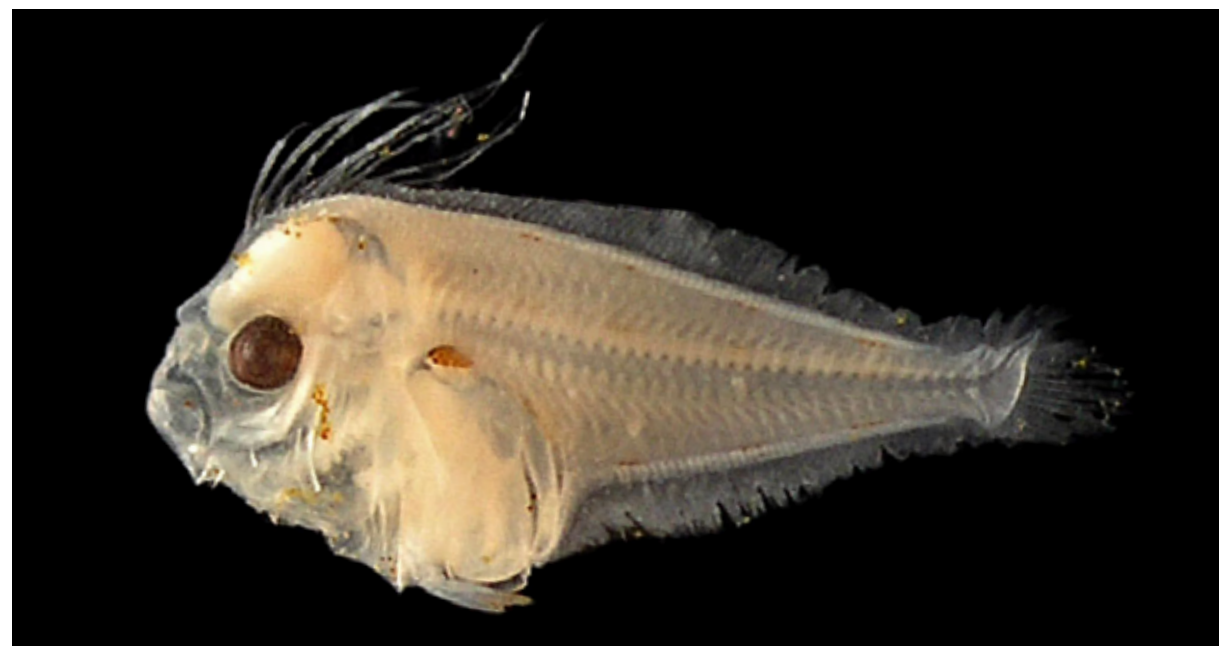

Figura 153 - B: DZUFRJ 13662; Flexão; CP 6,5 mm. 


\section{Família Bothidae}

A família Bothidae é marinha e ocorre nos oceanos Atlântico, Índico e Pacífico. Compreende 20 gêneros com aproximadamente 140 espécies. As larvas são bilateralmente simétricas e o corpo é alto e lateralmente comprimido. O primeiro ou segundo raio da nadadeira dorsal é alongado. Antes da metamorfose as larvas perdem o raio alongado. As nadadeiras dorsal e anal são longas e contínuas com a base da nadadeira caudal fazendo com que o pedúnculo seja muito pequeno ou ausente. Os olhos após a metamorfose estão posicionados do lado esquerdo da cabeça.

No Brasil já foram identificadas 12 espécies nas fases de larva e adulto. Nesse estudo são contempladas as espécies Bothus ocellatus e Chascanopsetta lugubris. 


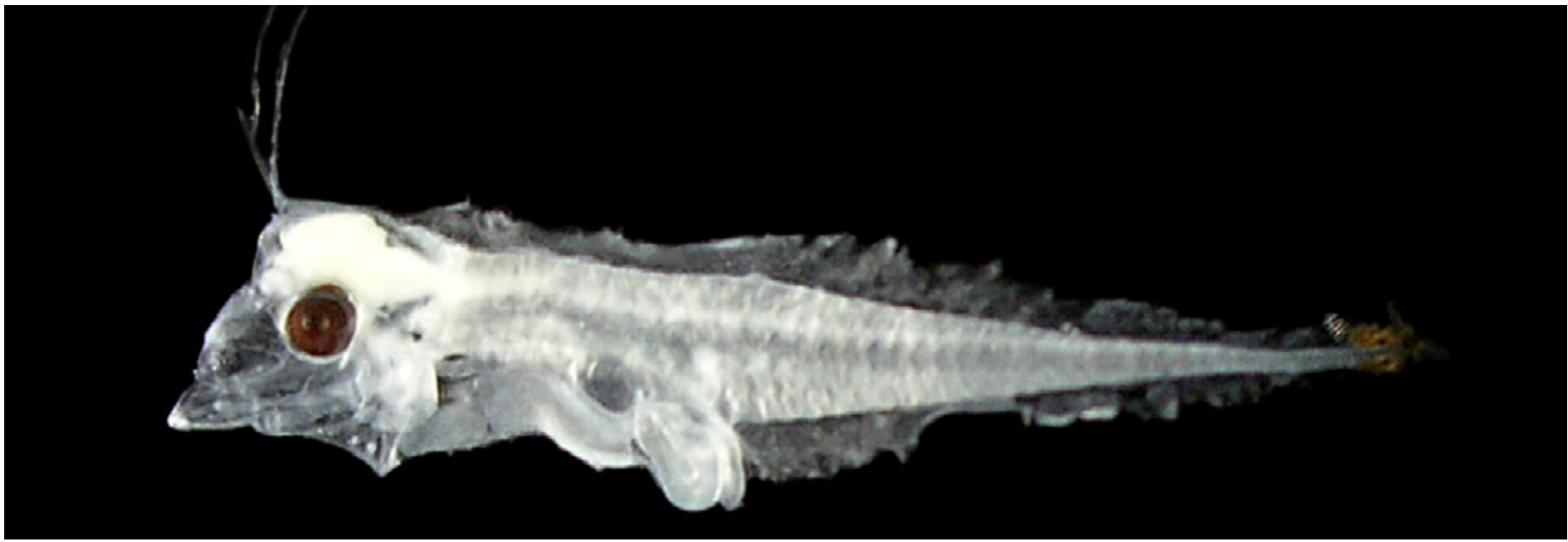

Figura 154 - A: Bothus ocellatus. DZUFRJ 25137 Pré-flexão; CP 4,1mm.

\section{Bothus ocellatus (Agassiz, 1831)}

As larvas em estágio de pré-flexão possuem o corpo alongado, muito comprimido, e o intestino faz uma volta. Tem pequenos melanóforos na extremidade da cauda. Durante os estágios de flexão e pós-flexão as larvas possuem o corpo mais robusto. O primeiro raio da nadadeira dorsal é alongado em todos os estágios de desenvolvimento e começa a diminuir durante a transformação. Em larvas maiores que 10 mm não tem nenhuma pigmentação. Raios da nadadeira dorsal: 76-91; raios da nadadeira anal: 58-69. O número de miômeros varia entre 35 e 37.

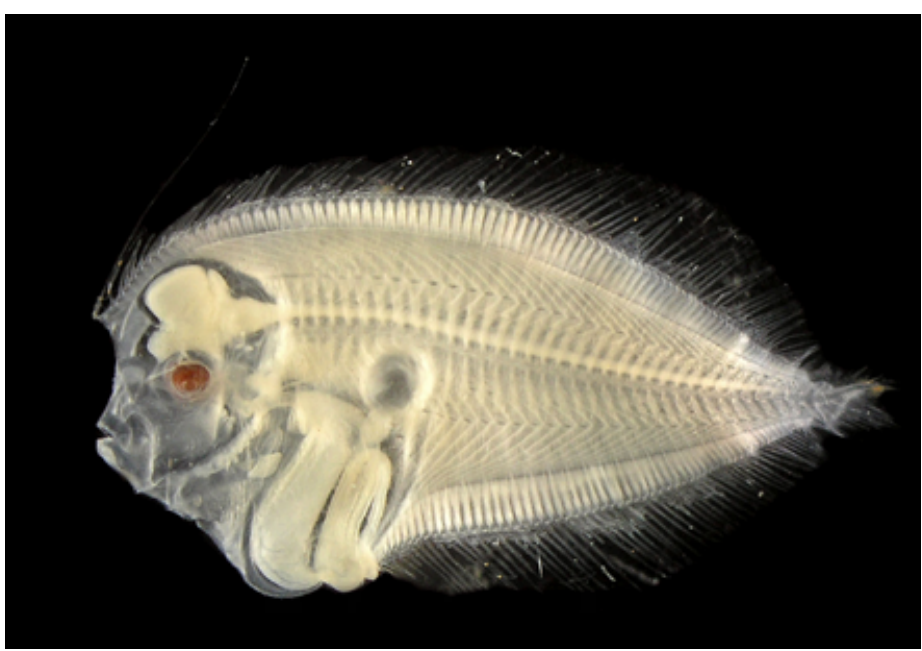

Figura 154 - B: DZUFRJ; 13165 Flexão; CP 7,5 mm.

Tamanho: pré-flexão 4,0-5,2 mm; flexão 7,3-7,6 mm; pós-flexão 11,5 mm; transformação 20,8 mm.

Habitat: espécie marinha, demersal, associada a formações coralinas, ocorre até $110 \mathrm{~m}$ de profundidade.

Nome vulgar: Linguado arco íris.

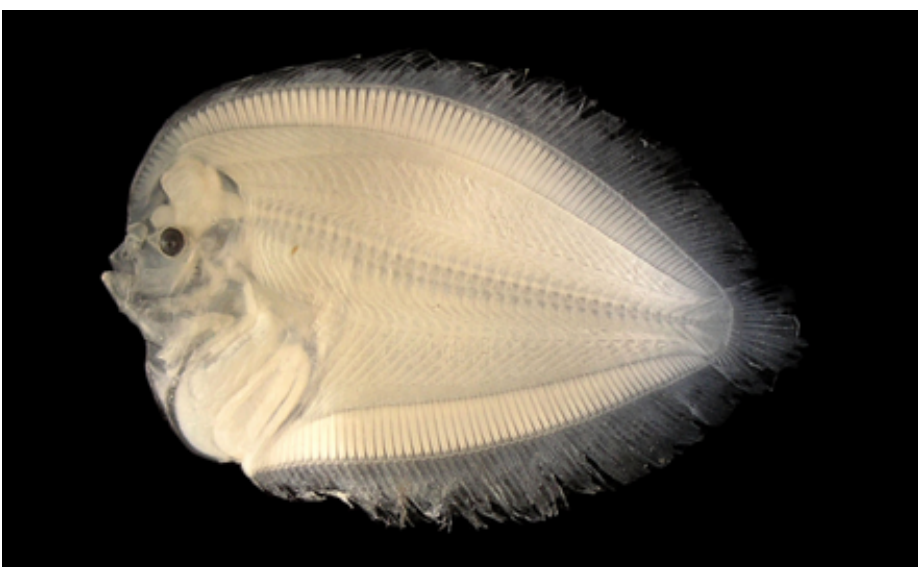

Figura 154 - C: DZUFRJ 11910; Pós-flexão; CP 12,0 mm.

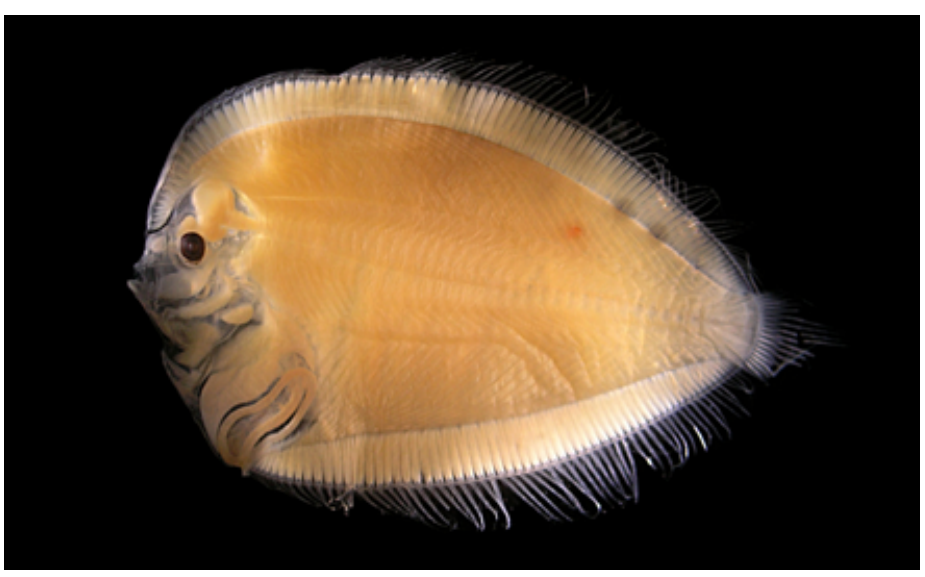

Figura 154 - D: DZUFRJ 19901; Transformação; CP 20,8 mm. 


\section{Georreferenciamento}

\begin{tabular}{|c|c|c|c|c|c|c|c|c|}
\hline DZUFRJ & Latitude (S) & Longitude (W) & Data & $\begin{array}{l}\text { Tipo de } \\
\text { arrasto }\end{array}$ & $\begin{array}{l}\text { Profundidade } \\
\text { de coleta }\end{array}$ & Rede & $\begin{array}{l}\text { Malha } \\
(\mu \mathrm{m})\end{array}$ & $\begin{array}{l}N^{\circ} \text {. de } \\
\text { inds. }\end{array}$ \\
\hline 481 & $22^{\circ} 33^{\prime} 37,0^{\prime \prime}$ & $040^{\circ} 19^{\prime} 10,0^{\prime \prime}$ & $17 / 05 / 2002$ & oblíquo & $50 \mathrm{~m}$ & bongô & 500 & 1 \\
\hline 510 & $22^{\circ} 38^{\prime} 25,0^{\prime \prime}$ & $040^{\circ} 17^{\prime} 41,0^{\prime \prime}$ & $19 / 05 / 2002$ & oblíquo & $40 \mathrm{~m}$ & bongô & 500 & 2 \\
\hline 550 & $22^{\circ} 34^{\prime} 05,0^{\prime \prime}$ & $040^{\circ} 19^{\prime} 40,0^{\prime \prime}$ & $17 / 05 / 2002$ & oblíquo & $600 \mathrm{~m}$ & cilíndrico-cônica & 500 & 2 \\
\hline 567 & $22^{\circ} 33^{\prime} 37,0^{\prime \prime}$ & $040^{\circ} 19^{\prime} 10,0^{\prime \prime}$ & $17 / 05 / 2002$ & oblíquo & $50 \mathrm{~m}$ & bongô & 330 & 1 \\
\hline 573 & $22^{\circ} 32^{\prime} 03,0^{\prime \prime}$ & $040^{\circ} 17^{\prime} 21,0^{\prime \prime}$ & $19 / 05 / 200$ & oblíquo & $30 \mathrm{~m}$ & bongô & 500 & 2 \\
\hline 607 & $22^{\circ} 38^{\prime} 29,0^{\prime \prime}$ & $040^{\circ} 17^{\prime} 40,0^{\prime \prime}$ & $18 / 05 / 2002$ & oblíquo & $800 \mathrm{~m}$ & cilíndrico-cônica & 500 & 1 \\
\hline 614 & $22^{\circ} 36^{\prime} 54,9^{\prime \prime}$ & $040^{\circ} 09^{\prime} 19,4^{\prime \prime}$ & $16 / 05 / 2002$ & oblíquo & $50 \mathrm{~m}$ & bongô & 500 & 3 \\
\hline 625 & $22^{\circ} 36^{\prime} 54,9^{\prime \prime}$ & $040^{\circ} 09^{\prime} 19,4^{\prime \prime}$ & $16 / 05 / 2002$ & oblíquo & $50 \mathrm{~m}$ & bongô & 330 & 7 \\
\hline 658 & $22^{\circ} 33^{\prime} 47,7^{\prime \prime}$ & $040^{\circ} 12^{\prime} 20,5^{\prime \prime}$ & $17 / 05 / 2002$ & oblíquo & $50 \mathrm{~m}$ & bongô & 500 & 1 \\
\hline 687 & $22^{\circ} 41^{\prime} 54,7^{\prime \prime}$ & $040^{\circ} 14^{\prime} 04,5^{\prime \prime}$ & $16 / 05 / 2002$ & oblíquo & $1.000 \mathrm{~m}$ & cilíndrico-cônica & 500 & 6 \\
\hline 697 & $22^{\circ} 37^{\prime} 35,5^{\prime \prime}$ & $040^{\circ} 09^{\prime} 32,8^{\prime \prime}$ & $16 / 05 / 2002$ & oblíquo & $1.000 \mathrm{~m}$ & cilíndrico-cônica & 500 & 2 \\
\hline 1333 & $22^{\circ} 06^{\prime} 37,8^{\prime \prime}$ & $039^{\circ} 49^{\prime} 44,8^{\prime \prime}$ & $10 / 05 / 2002$ & oblíquo & até a termoclina & bongô & 330 & 1 \\
\hline 2621 & $22^{\circ} 35^{\prime} 08,5^{\prime \prime}$ & $039^{\circ} 46^{\prime} 22,3^{\prime \prime}$ & $07 / 12 / 2002$ & horizontal & superfície & nêuston & 500 & 1 \\
\hline 16287 & $22^{\circ} 08^{\prime} 14,9^{\prime \prime}$ & $039^{\circ} 46^{\prime} 34,6^{\prime \prime}$ & $11 / 05 / 2002$ & oblíquo & até a termoclina & bongô & 330 & 2 \\
\hline 19901 & $22^{\circ} 31^{\prime} 40,9^{\prime \prime}$ & $040^{\circ} 02^{\prime} 39,6^{\prime \prime}$ & 07/11/2001 & oblíquo & $1.000 \mathrm{~m}$ & cilíndrico-cônica & 500 & 1 \\
\hline 19902 & $22^{\circ} 02^{\prime} 35,2^{\prime \prime}$ & $039^{\circ} 43^{\prime} 18,2^{\prime \prime}$ & $04 / 12 / 2002$ & vertical & $700-1.200 \mathrm{~m}$ & cilíndrico-cônica & 200 & 2 \\
\hline 19904 & $22^{\circ} 35^{\prime} 08,5^{\prime \prime}$ & $039^{\circ} 46^{\prime} 22,3^{\prime \prime}$ & $07 / 12 / 2002$ & vertical & $200-500 m$ & cilíndrico-cônica & 200 & 1 \\
\hline 19905 & $22^{\circ} 02^{\prime} 35,2^{\prime \prime}$ & $039^{\circ} 43^{\prime} 18,2^{\prime \prime}$ & $04 / 12 / 2002$ & vertical & $700-1.200 m$ & cilíndrico-cônica & 500 & 3 \\
\hline
\end{tabular}

Referências: Lara, 2006b; Macedo \& Monteiro-Ribas, 2006; Fahay, 2007. 


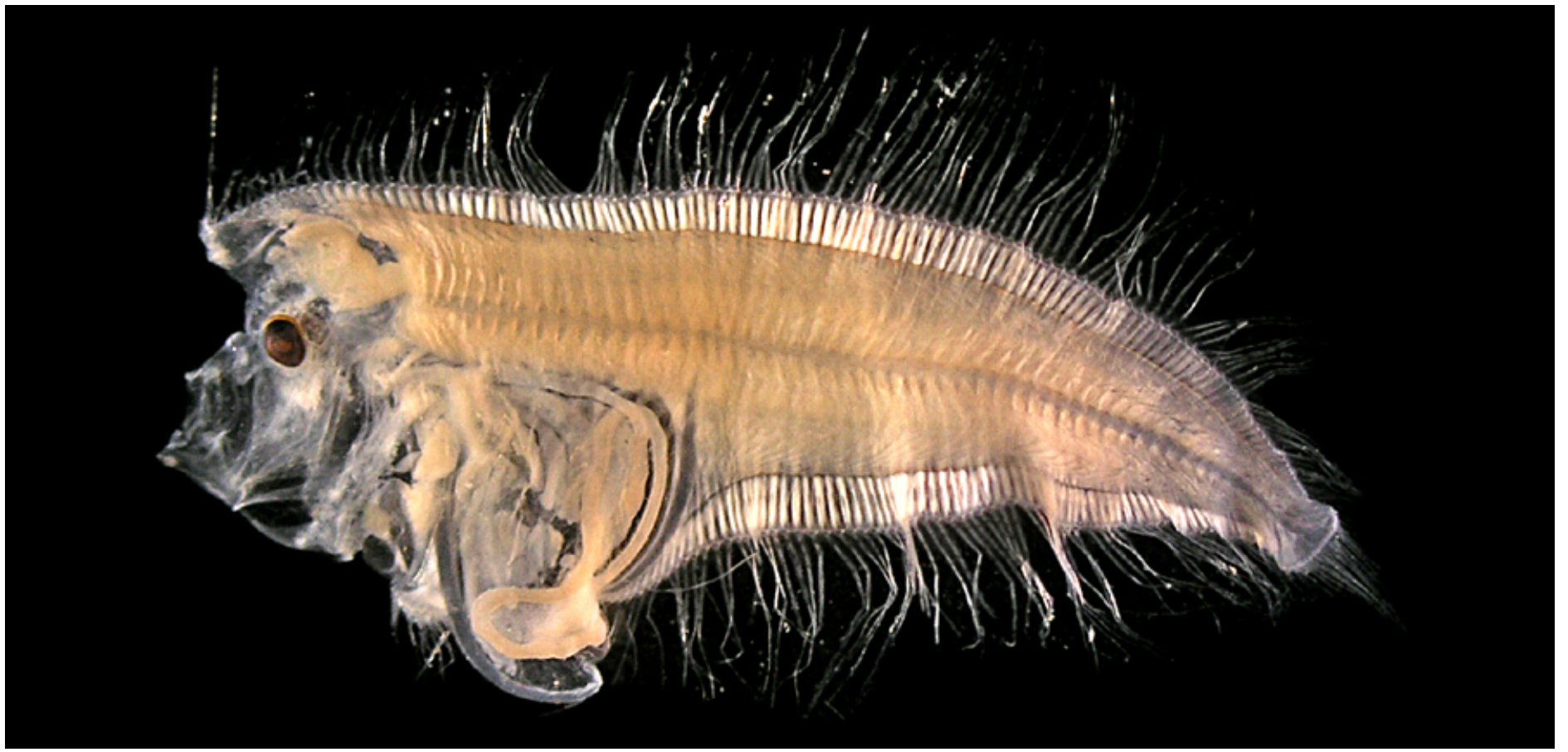

Figura 155: Chascanopsetta lugubris. DZUFRJ 7499; Pós-flexão; CP 16,5mm.

\section{Chascanopsetta lugubris Alcock, 1894}

As larvas em estágio de pós-flexão têm o corpo mais alto que alongado. Possui o segundo raio da nadadeira dorsal alongado e o intestino é expandido, passando da margem ventral do corpo. Raios da nadadeira dorsal: 111-122; raios da nadadeira anal: 76-85. Possui um total de 55 miômeros.

Tamanho: pós-flexão 16,5 mm.

Habitat: espécie marinha, batidemersal, ocorre entre 60 e 977 m de profundidade.

Nome vulgar: Linguado.

\section{Georreferenciamento}

\begin{tabular}{|c|c|c|c|c|c|c|c|c|}
\hline DZUFRJ & Latitude (S) & Longitude (W) & Data & $\begin{array}{c}\text { Tipo de } \\
\text { arrasto }\end{array}$ & $\begin{array}{c}\text { Profundidade } \\
\text { de coleta }\end{array}$ & Rede & $\begin{array}{c}\text { Malha } \\
\text { ( } \boldsymbol{\mu m})\end{array}$ & $\begin{array}{c}\mathbf{N}^{\circ} \text {. de } \\
\text { inds. }\end{array}$ \\
\hline 7499 & $21^{\circ} 58^{\prime} 31,0^{\prime \prime}$ & $039^{\circ} 50^{\prime} 29,7^{\prime \prime}$ & $10 / 10 / 2001$ & oblíquo & $1.000 \mathrm{~m}$ & cilíndrico-cônica & 500 & 1 \\
\hline
\end{tabular}

Referências: Lara, 2006b; Fahay, 2007. 


\section{Família Cynoglossidae}

A família Cynoglossidae é marinha, mas algumas espécies entram em ambientes de água doce. Ocorre nos mares tropicais e subtropicais. Compreende três gêneros com 127 espécies. As larvas possuem o corpo alongado e lateralmente comprimido. O intestino forma uma alça e é projetado para a região ventral do corpo. O número de raios alongados da nadadeira dorsal, o padrão de pigmentação nas margens dorsal e ventral do corpo e a presença ou ausência de um apêndice cônico na região ventral do abdome são características importantes para a identificação das espécies.

No Brasil já foram identificadas 12 espécies nas fases de larva e adulto. Nesse estudo é contemplada a espécie Symphurus kyaropterygium. 


\section{Symphurus}

kyaropterygium

Menezes \&

\section{Benvegnú, 1976}

Tem o primeiro raio da nadadeira dorsal curto, seguido de quatro raios longos. Possui quatro blocos de pequenos melanóforos nas regiões dorsal e ventral do corpo. Tem pequenos melanóforos na região do trato digestório.

Tamanho: flexão 6,6-7,5 mm.

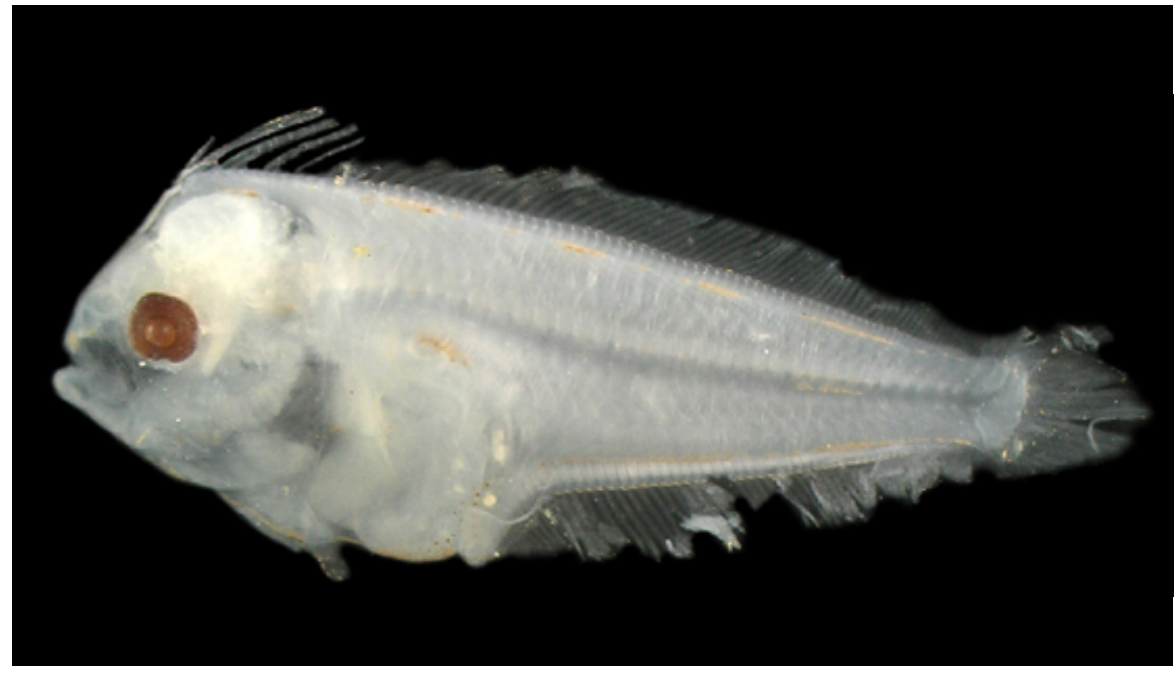

Figura 156 - Symphurus kyaropterygium. DZUFRJ 1063; Flexão; CP 6,6 mm.

Habitat: espécie marinha, demersal, ocorre entre 36 e $69 \mathrm{~m}$ de profundidade.

Nome vulgar: Língua de vaca.

\section{Georreferenciamento}

\begin{tabular}{|c|c|c|c|c|c|c|c|c|}
\hline DZUFR & Latitude (S) & Longitude (W) & Data & $\begin{array}{c}\text { Tipo de } \\
\text { arrasto }\end{array}$ & $\begin{array}{c}\text { Profundidade } \\
\text { de coleta }\end{array}$ & Rede & $\begin{array}{c}\text { Malha } \\
\text { ( } \boldsymbol{\mu m})\end{array}$ & $\begin{array}{c}\text { No. de } \\
\text { inds. }\end{array}$ \\
\hline 7500 & $21^{\circ} 54^{\prime} 36,5^{\prime \prime}$ & $039^{\circ} 45^{\prime} 20,0^{\prime \prime}$ & $10 / 10 / 2001$ & oblíquo & $1.000 \mathrm{~m}$ & cilíndrico-cônica & 500 & 1 \\
\hline 19900 & $22^{\circ} 32^{\prime} 50,0^{\prime \prime}$ & $040^{\circ} 04^{\prime} 09,9^{\prime \prime}$ & $06 / 11 / 2001$ & oblíquo & $1.000 \mathrm{~m}$ & cilíndrico-cônica & 500 & 1 \\
\hline
\end{tabular}

Referências: Kurtz \& Matsuura, 1994; Macedo \& Monteiro-Ribas, 2006. 